\title{
Social Networking and Teaching: An Australian Case Study
}

\author{
Shona Leitch and Matthew J. Warren \\ School of Information Systems, Faculty of Business and Law, \\ Deakin University, Burwood, Victoria, Australia
}

\section{shona@deakin.edu.au; matthew.warren@deakin.edu.au}

\begin{abstract}
In recent years, the Internet has impacted all aspects of modern society. We have now seen the phenomenon of social networking and the impact that this had upon all aspects of modern society including higher education. An issue is how can these social networking technologies relate to tertiary education and how can they be used in this educational context. This paper is based on two case studies which were conducted at an Australian University into the usage of two social networking systems in a teaching environment. The results of these case studies were assessed using a socio-technical framework.
\end{abstract}

Keywords: Social Networking, Socio-Technical, Education, Facebook and Twitter.

\section{Introduction}

The on-line learning phenomenon has become more widespread in recent years with many learning institutions adapting ways of incorporating modern technology into learning skills and objectives to facilitate students learning. On-line learning has becoming an ever-increasing way of facilitating education to students who are unable to attend a traditional on-campus university as well as supporting on-campus teaching (Leitch \& Warren, 2008b).

Social networking has impacted all aspects of modern society including the educational arena (Mason \& Rennie, 2008). One of the attributes of social networking is the ability to facilitate engagement between individuals. In an educational environment, engagement between a student and academic is of key importance and social networking may be able to facilitate this engagement. Another issue that relates to social networking is the large number of technologies that can be used however some of these technologies may be more suited to an educational environment than others.

Importantly is the nexus between student and academic, the concern is how can this nexus be taken into account when on-line education learning systems are being used (Leitch \& Warren,

Material published as part of this publication, either on-line or in print, is copyrighted by the Informing Science Institute. Permission to make digital or paper copy of part or all of these works for personal or classroom use is granted without fee provided that the copies are not made or distributed for profit or commercial advantage AND that copies 1) bear this notice in full and 2) give the full citation on the first page. It is permissible to abstract these works so long as credit is given. To copy in all other cases or to republish or to post on a server or to redistribute to lists requires specific permission and payment of a fee. Contact HPublisher@InformingScience.orgH to request redistribution permission. 2008a) and whether social networking provide this connection.

The global use of the Internet has developed in recent years and now impacts all aspects of society from business, education to social activities. The global impact of the Internet is shown by Table 1 . 
Table 1 Global Internet Usage (InternetWorld, 2009)

\begin{tabular}{|l|l|l|}
\hline Region & $\begin{array}{l}\text { Number } \\
\text { (millions of users) }\end{array}$ & $\begin{array}{l}\text { \% Regional } \\
\text { Penetration }\end{array}$ \\
\hline Asia & 704.2 & 18.5 \\
\hline Europe & 402.4 & 50.1 \\
\hline North America & 251.7 & 73.9 \\
\hline Latin America/Caribbean & 175.8 & 30 \\
\hline Africa & 65.9 & 6.7 \\
\hline Middle East & 48 & 23.7 \\
\hline Oceania/Australia & 20.8 & 60.1 \\
\hline World Average & & 24.7 \\
\hline
\end{tabular}

The environment of increasing numbers of Internet users and a faster Internet, allowed for Web 2.0 to globally develop (Shuen, 2008).

The paper will contain a discussion of social networking technologies and present two case studies where these technologies have been used in a teaching context. The case studies will then be assessed using a socio-technical approach.

\section{Social Networking Technologies}

Social networking systems such as Facebook are an ever evolving and developing means of social interaction, which is not only being used to disseminate information to family, friends and colleagues but as a way of meeting and interacting with "strangers" through the advent of a large number of social applications (Warren, 2010).

The emergence of Web 2.0 and related internet sites such as Facebook has had a major impact upon the Internet in recent years. One of the interesting aspects of Facebook is the use of third party applications and the interactions that this allows. This means that an individual Facebook page now act as a web page, blog, instant messenger, email system and the use of third parties applications allows for real time functionality (DiMicco and Millen, 2007; Shuen, 2008).

Two of the most widely used social networking technologies are Facebook and Twitter.

\section{Facebook Social Networking Site}

Facebook's inception took place in 2004 and in February 2010 Facebook announced it had reached its 400 millionth registered user (Schonfeld, 2010); by 2011 this figure was reported as 500 million (Facebook, 2011). Facebook is a social utility that helps people communicate more efficiently with their friends, family and co-workers. The Facebook environment means that anyone can sign up for Facebook and interact with the people they know in a trusted environment (Facebook, 2009). Facebook has had a global impact, in 2010 there were more than 350,000 active applications currently on the Facebook platform; and in 2011,"900 million objects that people interact with (pages, groups, events and community pages)" and more than $50 \%$ of Facebook users logging into the site every day (Facebook 2011) as well as more than 200 million active users currently accessing Facebook through their mobile devices (Facebook, 2011), a dramatic increase from 100 million in 2010 (Facebook, 2010). 


\section{Twitter Service}

Micro-blog services such as Twitter, Yammer, Plurk and Emote enable micro-blog users to post 140 character-long messages which can then be accessed by their followers. Some users restrict access to their micro-blog streams whereas others make theirs accessible to the public. The format of micro-blog postings has evolved with several micro-blog services also supporting multimedia attachments and URL links. Online social networks such as Facebook support microblogging through the user status update function (Lee \& Warren, 2010).

As a mass communication channel, micro-blogs are not edited by reviewers or editors prior to publication. Unlike a full-fledged online diary or weblog, micro-blog entries are short and swift. Micro-blogs are a transparent, one-to-many online conversational platform. Users could post micro-blog entries through web browsers, web-based applications, mobile applications, or via emails and SMS text messages. Followers of micro-blogs could post a reply to a micro-blog entry, or repost the original micro-blog entry in their own micro-blog stream as a re-tweet. Although micro-blogs are often compared to SMS text messages, micro-blogs are relatively more effective that the former when used for reaching multiple followers simultaneously. Unlike SMS text messages, micro-blog followers have a choice of whether to subscribe to a micro-blog stream, or just browse through a sea of micro-blog streams accessible to them (Lee \& Warren, 2010).

Twitter was developed in 2006 as a side project, for a podcasting service called Odeo (this service ceased operations at the start of 2010). The aim of Twitter was to allow users to follow others without having to reciprocate and allow themselves to be followed and all posts were public by default and limited to 140 characters so they could fit inside cellphone text messages ("Why Twitter's C.E.O. demoted himself," 2010).

Twitter is the most widely used of the Micro blogging organisations and of September 2010, the following data clearly demonstrates its enormous impact (Twitter, 2010):

- Twitter has 75 million registered users;

- 95 million tweets are written per day;

- Twitter has 300 employees.

The future projected growth of Twitter is 15 million users per month, or about half a million users per day (Murphy, 2010).

\section{The Design of Online Teaching and Learning Systems}

Research conducted in 2008 with current Deakin University undergraduate students found that they were interested in using social software within their learning environment but that little was currently used within the current teaching and learning system environment (Leitch \& Warren, 2008b).

Social networking has been proposed as a social environment (Stafford et al, 2004) and has taken the use of media to a $3^{\text {rd }}$ level (beyond content media and communication media). Some research into the use of Facebook by educators found that students believed utilising Facebook would produce "higher levels of motivation and affective learning and a more positive classroom environment" (Mazer et al, 2007). Most students in a tertiary environment are involved in a number of online discussion forums because of the common use of software such as DSO (Deakin Studies Online a systems based on Blackboard), however when these discussions are not part of the assessment process the interest and participation of students tends to wane with the first month of a unit (English \& Duncan-Howell, 2008). It is therefore proposed that rather than accepting this lack of participation that educators use software which is more appealing and more commonly used by students and one which provides a more "social environment". It is this social environ- 
ment that the researchers wish to explore in relation to its use in a tertiary teaching and learning environment. In an Australian context tertiary education refers to education at the University Level and could encapsulate undergraduate study e.g. Bachelor degree study or postgraduate study, e.g. Master degree study.

As Facebook was developed initially for college based users and the largest part of a university unit cohort can now be labeled as "digital natives" (Prensky, 2001); it seems appropriate then to take this software back to the university classroom and use it to educate students in a familiar online environment as well as fostering inter-personal relationships amongst student classes. Other studies have found some success in the use of Facebook within particular student cohorts (McCarthy, 2010).

\section{The Use of Social Networking Technologies - A Practical Study}

Research was conducted on a cohort of students enrolled in a number of Faculty of Business and Law units at Deakin University, Australia during trimester 3, 2009 and trimester 1, 2010. One unit was a Masters of Information System unit and the other was a core Bachelor of Commerce unit. These students were enrolled in a number of courses, including, Master of Information Systems, Master of Business Administration and the Bachelor of Commerce. Facebook and Twitter was used for a variety of teaching related activities as well as student engagement activities during the semester and informal feedback was gathered.

\section{Twitter Case Study}

Twitter was selected as one of the technologies to be used to attempt to support students at Deakin University, Australia. Twitter was implemented in MSC767 (Business Security Management) which is a postgraduate unit offered to Faculty of Business and Law students enrolled in the Masters of Information Systems, Masters of Commerce and Masters of Business Administration. The Twitter support augmented existing online technologies for students, in the form of an online teaching environment (DSO), audio recordings of the lectures and traditional e-mail support, e.g. weekly emails reflecting on the topic of the week. The aim of the Twitter support was to give students additional information about current trends in information security, the intention was to encourage students to contemplate current events. Twitter was also used to remind students about key events, e.g. pending assignment submission dates.

Students were given information regarding the Twitter support (what to expect, why it was being used etc.) in a face to face classroom environment as well as on the online teaching and learning system that is mandated by Deakin University to be used. A number of issues resulted from this:

The initial invitation was sent via the student's official Deakin email address. The some of the issues encountered were:

- Not every student checked their official email account;

- Students who enrolled late into the unit had not been sent the initial invite. This meant that a follow up procedure had to be implemented to identify late student enrolments and then send them an invite;

- Some students did not know anything about Twitter and wanted more advice on what it was and how it could be used;

- One of the off campus students worked at a bank and their organisation had a policy limiting access to social networking technology, this meant that the student could not be- 
come part of the MSC767 twitter channel and the student did not have internet access at home. The student was upset because they felt they were disadvantaged.

Fifty four students were enrolled in the unit that was selected, of this cohort, 14 students became followers of the MSC767 twitter stream that represented 26\% of the total class. During trimester 1, 19 tweets were made to the MSC767 student cohort via Twitter. The tweets took the form of:

- Hints on revision;

- Reminder on assignment dates;

- The majority of the tweets related to reposting topical security stories that were current in the media.

A typical tweet is shown in figure 1, this tweet was used to reinforce one of the topics that we had discussed in the lectures; the impact of security and privacy on social networking sites such as Facebook.

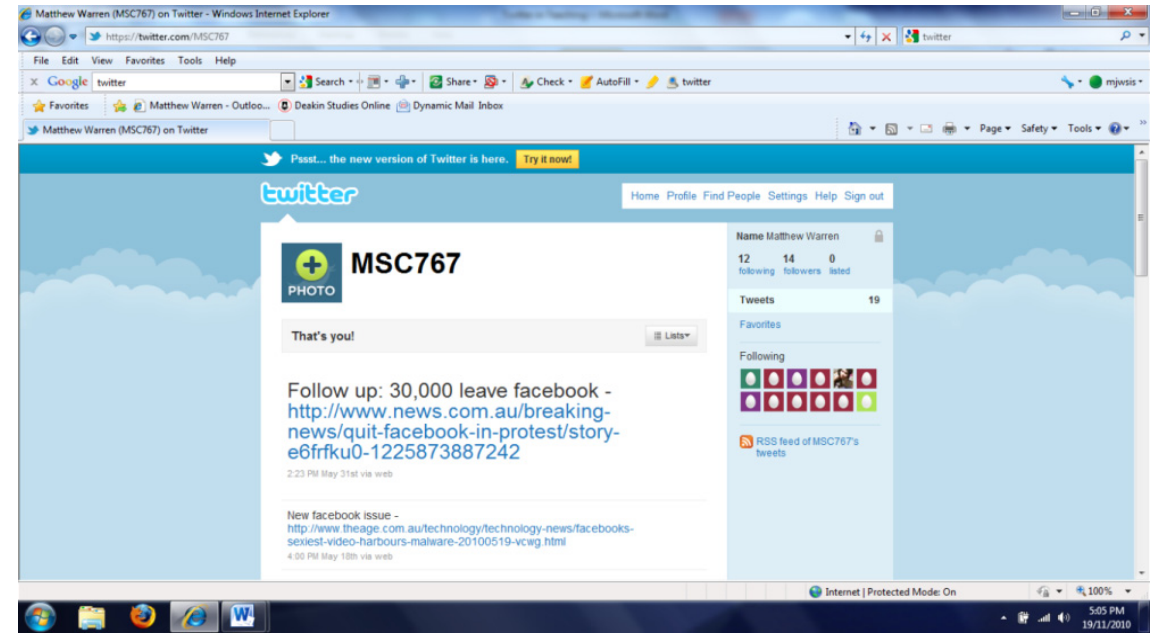

Figure 1 An example MSC767 tweet

Deakin University has a formal system where students give feedback regarding the units they have taken during that trimester. This feedback takes the form or qualitative and quantitative data. The quantitative data is a score out of 5 (with 5 being the highest). The unit received the following quantitative evaluations:

- On campus 4.23;

- Off Campus 4.67 (the highest score within the School of Information Systems for Trimester 1, 2010).

The results showed an increase of 0.2 compared to the same trimester in 2009. It should be noted that the use of teaching evaluation is indicative of general trends as the whole class did not use Twitter.

And some of the qualitative comments were:

- A good unit;

- Great support and feedback;

- Audio lectures were good and concise. Use of Twitter was good. 
- Great lecturer and wish I had done it on campus so we could have engaged face to face more! Thanks very much.

\section{Facebook Case Study}

Facebook was the second social networking technology to be used in a teaching and learning situation as a part of this study. As in the first Twitter example, Facebook was also used to support a unit of study at Deakin University, Australia; the selected unit was MSC120 (Business Information Systems). This unit was a core first year undergraduate unit offered to Faculty of Business and Law students enrolled in the Bachelor of Business Information Systems, Bachelor of Commerce, Bachelor of Management and the unit can be taken as an elective from a number of other undergraduate courses. This support again augmented existing online technologies for students, in the form of an online teaching environment (DSO) and audio recordings of the lectures. The Facebook support provided students with an opportunity to be provided with additional information about current trends in information systems and to encourage students reflect on current general Information Systems events. Facebook was also intended to be used in a social context to give added value to the teaching and learning experience.

There were a total of 96 students enrolled in the unit. Of the student cohort, 29 students became members of the MSC120 Facebook that represented 30\% of the total class. Additional members of the Facebook group included the group convenor and two academic staff members.

During trimester 3, a number of wall posts were made to the MSC120 Facebook Wall as well as some specific discussion topics.

The post took the form of:

- Reflective questions e.g. what is Information Systems?

- Current news topics, e.g. launch of the Apple iPad;

- Social postings.

The Facebook group profile page is shown in Figure 2; this profile page was used to reinforce topics that were discussed in the lectures.

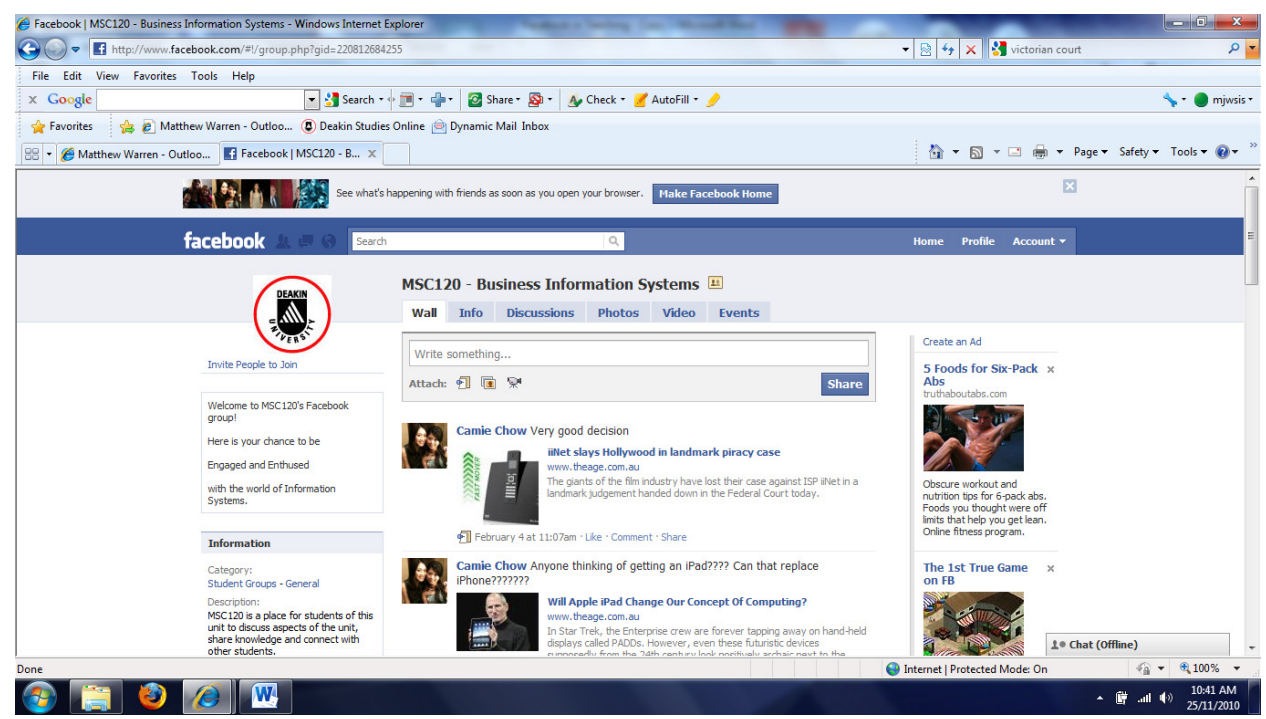

Figure 2 The MSC120 Facebook Group 
The use of Facebook within the context of the unit was explained in the first lecture. Information was also posted on the DSO (Deakin Studies Online) MSC120 site for off campus students. Students were informed that participation was voluntary.

The Facebook postings and responses throughout the trimester highlighted some issues:

- There were no responses to the subject related postings or the discussion topics. The social postings however gathered a number of responses, e.g. "what are you guys doing for Christmas?" resulted in a total 9 postings;

- There were no direct student contributions to the group, only responses to convener initiated social posts.

The unit received the following quantitative evaluations:
- On campus
3.57 ;

- Off Campus

3.71 .

The results showed a decrease of 0.4 compared to the same trimester in 2008. It should be noted that the use of teaching evaluation is indicative of general trends as the whole class did not use Facebook.

There were no qualitative comments that related to this study.

\section{Socio-Technical Analysis of Teaching Case Studies}

Historically, the main illustration of the socio-technical (participational) approach is the ETHICS

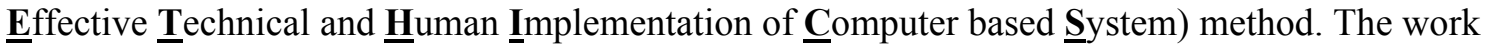
on ETHICS was undertaken by Enid Mumford of the Manchester Business School, UK (Mumford, 1983a). It is this participational (also referred to as a socio-technical approach) approach that focuses upon people and procedures. This socio-technical approach is defined as "one which recognises the interaction of technology and people and produces work systems which are both technically efficient and have social characteristics which lead to high job satisfaction" (Mumford, 1983b).

The original ETHICS method was developed in the UK in the late 1960's to deal with the impending information revolution (Mumford and Ward, 1968) of the 1970's. Around this time Mumford (1969) examined the impact of implementing computers within organisations, and determined that the successful introduction of technical changes required an understanding of the human aspects.

A continuation of the research saw continued development in the area of participation and how different forms of participation could be used within the ETHICS method (Mumford \& Henshall, 1979). The introduction of new technology into an organisation created the conceptual view of thinking of technology as a human issue (Mumford, 1995) and the main attributes were:

- User requirements: New technology directly affects users. User requirements should be incorporated fully into the system design from the start so that the system that is designed actually complies with user requirements; and

- User job satisfaction: The way in which computer a system usually has a direct affect upon the user and the way they use the system. If the user is unsatisfied with the system they will become less motivated and users will take longer to carry out tasks, or might not even use the system at all.

The researchers have modified the research by Enid Mumford to relate to social networking systems. The aim of the modification was to gain an understanding of the impact of social network- 
ing from a socio-technical viewpoint. The researchers modified the key criteria in regards to technology being a human issue in the following manner:

- Requirement: Social networking is about engagement, the issue is the required level of the engagement in terms of social connectivity or the required level of information being delivered;

- Satisfaction: The satisfaction concerns to the interaction of the social networking systems and the level of the information exchange that is occurring and the type of information being exchanged, e.g. social, factual, video, images, audio, etc;

- Context: The context relates to where the social engagement is taking place, e.g. formal context, information, community of special interest, etc.

The new conceptual view of technology as a human issue in the social networking age is shown in figure 3.

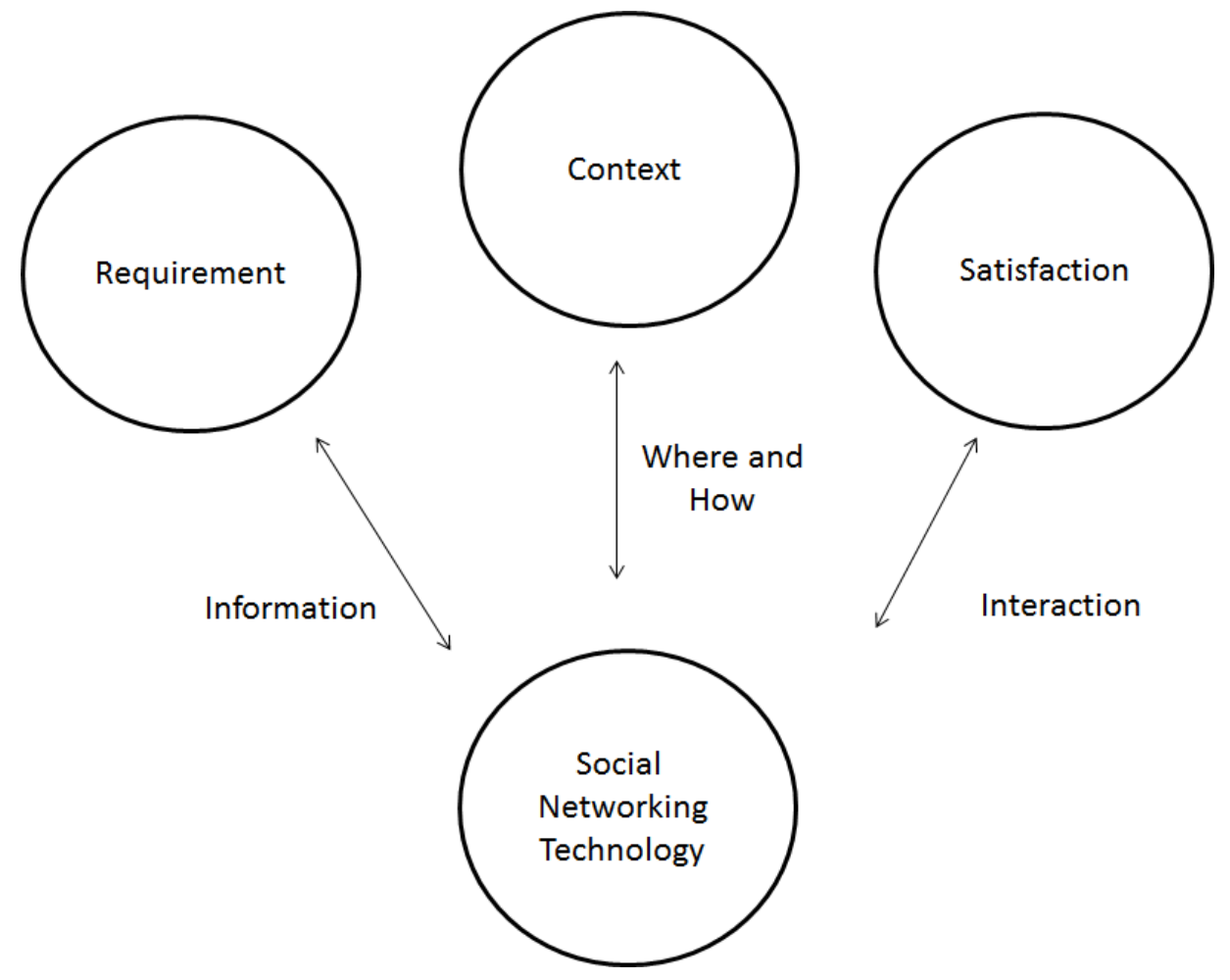

Figure 3: The conceptual view of technology as a human issue

The analysis of the two social networking systems case studies against the human and technology criteria is shown in Tables 2 and 3. 
Table 2: Assessment of Facebook

\begin{tabular}{|l|l|}
\hline Requirement & Facebook \\
\hline Context & $\begin{array}{l}\text { Technology related stories and discussion were } \\
\text { posted. Feedback from students was only received } \\
\text { when social questions were asked. }\end{array}$ \\
\hline Satisfaction & $\begin{array}{l}\text { The context was a social context. The MSC120 group } \\
\text { was one of many Facebook groups that the student } \\
\text { may be a member of. The information was provided } \\
\text { as links e.g. links to news items or text postings. }\end{array}$ \\
\hline $\begin{array}{l}\text { Limited. This is reflected by limited postings and no } \\
\text { positive feedback. }\end{array}$ \\
\hline
\end{tabular}

Table 3: Assessment of Twitter

\begin{tabular}{|l|l|}
\hline Requirement & Twitter \\
\hline Context & $\begin{array}{l}\text { Technology related stories and unit related informa- } \\
\text { tion was distributed. There was no feedback re- } \\
\text { quired. }\end{array}$ \\
\hline Satisfaction & $\begin{array}{l}\text { The context was a formal context. By joining the } \\
\text { MSC767 Twitter channel only information about the } \\
\text { unit would be provided. The information supplied } \\
\text { was in the form of links e.g. links to news items or } \\
\text { text. }\end{array}$ \\
\hline & $\begin{array}{l}\text { Positive. This was reflected by positive qualitative } \\
\text { comments and increased quantitative scores } \\
\text { through the Deakin University teaching evaluation } \\
\text { system. }\end{array}$ \\
\hline
\end{tabular}

Based upon the human and technological assessment some key conclusions of the two social networking case studies can be drawn.

The general conclusions and findings of the Facebook case study are:

- The Facebook student cohort was a first year student cohort and may have lacked maturity;

- Students were required to use two different systems for information and discussion (DSO and Facebook) with no integration;

- The majority of Facebook's use in the wider context is for social interaction rather than work/business/teaching and therefore students did not feel connected in using it in a work related sense.

The key findings are:

- The lack of satisfaction by the student cohort using Facebook may be due to the limited social interaction. Meaning that students may not want to formally engage educationally 
using a technology they normally use for social purposes. For example, taking part in a formal debate of topics when they are used to using Facebook in a very informal manner;

- The context of the postings was limited, for example, links to content related stories and did not fully utilize the functionality of Facebook that some of the students may be more familiar with, for example, links to different type of media, applications;

- As mentioned before Facebook has a very informal context, so trying to formalise the context by using it in a teaching situation may cause resistance.

The general conclusions and findings of the Twitter case study are:

- The student cohort was composed of postgraduate students who may already use the technology in a more mature manner, e.g. for professional purposes;

- Twitter technology allowed for the information to be distributed via a number of different technologies, from mobile computing devices to traditional computing devices which may have best suited more of the student cohort involved in the study;

- Twitter is set up for the limited exchange of information. This feature of the technology means there is less expectation that the students engage in discussion and collaboration.

The key findings are:

- Information was disseminated to the MSC767 Twitter channel followers in a formalised manner, e.g. tweets. The MSC767 Twitter channel highlights the formal aspects of Twitter, e.g. to engage with the Twitter channel you need to formally subscribe and the focus of Twitter is more concerned with information exchange rather than social interaction;

- In terms of the context postings, students would have accepted that the tweets would be limited in terms of size and information being delivered, e.g. short text format;

- Twitter has a formal context, to receive information or view (tweets) from people e.g. politicians, or organisations that students are interested in.

\section{Conclusion}

This paper has reflected upon the use of social networking technologies in an educational context, focusing particularly on the use of Facebook and Twitter. The study has indicated that the technologies relate to different modes of engagement. Facebook allows for greater interaction whereas Twitter allows for the receipt of more direct, focused information. In terms of the case studies put forward by this paper, it has highlighted the advantages and disadvantages of using social networking technologies in an educational context. The socio-technical analysis evaluated the use of the two distinct social networking technologies by the different student cohorts. It clearly showed that Twitter performed more effectively when assessed against requirement, context and satisfaction whereas Facebook performed more poorly in each of these three assessable areas.

A limitation of this study could be the fact that it was undertaken within an Australian University, future comparative studies would ascertain if there are cultural or national differences in the relation to the use of social networking technologies in an educational context. 


\section{References}

Dennen, V. (2008). Pedagogical lurking: Student engagement in non-posting discussion behaviour. Computers in Human Behavior, 24, 1624-1633.

DiMicco, J. M., \& Millen, D. R. (2007). Identity management: Multiple presentations of self in Facebook. Proceedings of the 2007 International ACM Conference on Supporting Group Work.

English, R., \& Duncan-Howell, J. (2008). Facebook goes to college: Using social networking tools to support students undertaking teaching practicum. Journal of Online Learning and Teaching, 4(4), 596601.

Facebook. (2009). Facebook facts. Retrieved $25^{\text {th }}$ September, 2009 from http://www.facebook.com/press/info.php?factsheet

Facebook. (2010). Facebook statistics. Retrieved $6^{\text {th }}$ June, 2010 from http://www.facebook.com/press/info.php?statistics

Facebook. (2011). Facebook statistics. Retrieved $3^{\text {rd }}$ March, 2011 from http://www.facebook.com/press/info.php?statistics

Lee, C., \& Warren, M. (2010). Micro-blogging in the Workplace. Proceedings of 8th Australian Information Security Management Conference, Perth, Australia.

Leitch, S., \& Warren, M. (2008a). Designing on-line learning systems using participation. ANZSYS Systems Conference 2008, Perth.

Leitch, S., \& Warren, M. (2008b). Analysing online teaching and learning systems using MEAD. Interdisciplinary Journal of E-Learning and Learning Objects, 4, 259-267. Retrieved from http://www.ijello.org/Volume4/IJELLOv4p259-267Leitch497.pdf

InternetWorld. (2009). Global internet statistics. Accessed $25^{\text {th }}$ September, 2009 from http://www.internetworldstats.com/stats.htm

Mason, R., \& Rennie, F. (2008). Learning and social networking handbook: Resources for higher education. USA: Routledge.

Mazer, J. P., Murphy, R. E., \& Simonds, C. J. (2007). I'll see you on "Facebook": The effects of computermediated teacher self-disclosure on student motivation, effective learning, and classroom climate. Communication Education, 56(1), 1-17.

McCarthy, J. (2010). Blended learning environments: Using social networking sites to enhance the first year experience. Australasian Journal of Educational Technology, 26(6), 729-740.

Mumford, E. (1969). Computers, planning and personnel management. Institute of Personnel Management, UK.

Mumford, E. (1983a). Designing participatively. Manchester, UK: Manchester Business School.

Mumford, E. (1983b). Designing human systems. Manchester, UK: Manchester Business School.

Mumford, E. (1995). Effective requirement analysis and systems design: The ethics method. UK: Macmillan.

Mumford, E., \& Henshall, D. (1979). A participative approach to computer systems design. UK: Associated Business Press.

Mumford, E., \& Ward, T.B. (1968). Computers: Planning for people. UK: Batsford Limited.

Murphy, D. (2010, November). Twitter: On-track for 200 million users by year's end. PC Magazine. Retrieved 7th November, 2010 from http://www.pcmag.com/article2/0,2817,2371826,00.asp

Schonfeld, E. (2010). Facebook closing in on 500 million visitors a month. TechCrunch. Retrieved on $18^{\text {th }}$ June 2010 from http://techcrunch.com/2010/04/21/facebook-500-million-visitors-comscore/

Shuen, A. (2008). Web 2.0: A strategy guide. O'Reilly Media. 
Stafford, T. F., Stafford, M. R., \& Schkade, L. L. (2004). Determining uses and gratifications for the Internet. Decision Sciences, 35(2), 259-288.

Twitter (2010). About Us. Retrieved 10th October, 2010 from http://twitter.com/about

Prenskym, M. (2001). Digital natives, digital immigrants, Part 1. On the Horizon, 9(5), 1-6.

Warren, M. (2010). Security risks of social networking systems [Keynote Presentation]. $4^{\text {th }}$ IEEE International Conference on Network and Systems Security, Melbourne, Australia.

Why Twitter's C.E.O. demoted himself. (2010, October 30). New York Times. Accessed 7th November, 2010 from http://www.nytimes.com/2010/10/31/technology/31ev.html?pagewanted $=2 \&$ r $=1 \&$ partner=rss\&emc=r $\underline{\text { SS }}$

\section{Biography}

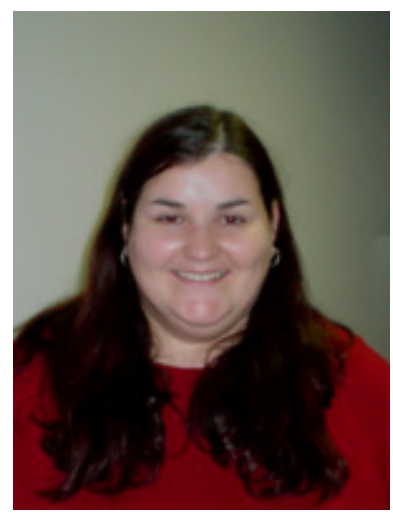

Dr. Shona Leitch is a Senior Lecturer in the School of Information Systems, Deakin University. Shona is originally from Scotland, emigrating to Australia in 1998. She obtained her BSc (Hons) in 1997 from the University of Plymouth in Psychology/Computing. Her main teaching and research focus is the area of education and Information Systems. Dr Leitch has gained a PhD entitled "A Systems Analysis and Design Strategy for Online Teaching and Learning Systems" from Deakin University.

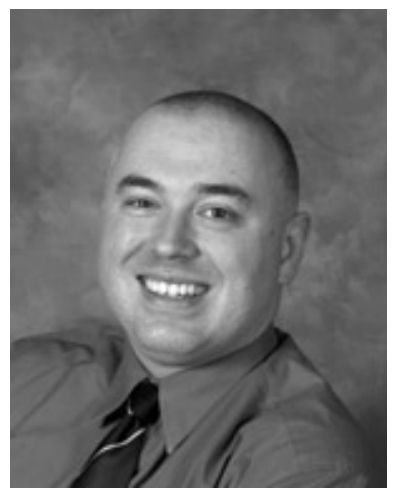

Professor Matthew Warren is the Head of School and a Professor in the School of Information System, Deakin University, Australia. He has a PhD in Information Security Management from Plymouth University, UK. Professor Warren is the former Chair of IFIP TC 11 Working Group 11.1 - Security Management and a former Director of the Australian Institute of Computer Ethics. 